\title{
Projeto Convulsivo Sinódico - exercício de experiência estética e de responsabilidade com o outro
}

\section{Convulsivo Sinódico Project - exercise of aesthetic experience and responsibility with the other}

\author{
Proyecto Convulsivo Sinódico - ejercicio de \\ experiencia estética y de responsabilidad con el otro
}

\author{
Sônia Aparecida ljano Batista ${ }^{1}$ \\ Vania Regina Boschetti ${ }^{1}$
}

DOI: http://dx.doi.org/10.20435/serie-estudos.v25i54.1257

\begin{abstract}
Resumo: A escola pública vive tempos difíceis, num contexto que visa a desqualificá-la, dando preferência aos investimentos privados na educação. Atualmente, é vista como inferior e incompetente perante os desafios da contemporaneidade. Na dimensão do conceito de ensaio de Larrosa, busca-se contribuir com a temática, analisando o Projeto Convulsivo Sinódico da E. E. "Prof. Carlos Augusto de Camargo", de Piedade, SP, criado e desenvolvido pela escola no período de 1993-2017, à maneira de Walter Benjamin, para quem o passado pode ser retomado e se revelar em novas formas no presente, e de Roger Chartier, na dimensão da história cultural, de como uma realidade é dada a ler. A metodologia utilizada é a pesquisa qualitativa junto aos Planos Diretores e de Gestão da Escola. Os resultados sinalizam caminhos a serem explorados na dimensão de Gabriel Perissé, em torno da alfabetização estética, uma forma de romper com as cristalizações nos modos de ver e viver a educação; e de Emmanuel Lévinas, acerca da responsabilidade com o outro.
\end{abstract}

Palavras chave: escola pública; experiência estética; prática escolar.

\begin{abstract}
The public school experiences difficult times, in a context that aims to disqualify it, giving preference to private investments in education. It is now seen as inferior and incompetent in the face of contemporary challenges. In the perspective of the concept testing of Larrosa, we sought to contribute with the subject, analyzing the Convulsivo Sinódico Project of the E. E. "Prof. Carlos Augusto de Camargo" from Piedade, SP, created and developed by the school in the period of 1993-2017, following Walter Benjamin, for whom the past can be resumed and revealed in new forms in the present, and Roger Chartier (1988, p. 17), in the dimension of cultural history, how a reality is made to read. The methodology used is the qualitative research with the Management and School Plans of the school. The results signal paths to be explored in the dimension of Gabriel
\end{abstract}

1 Universidade de Sorocaba (UNISO), Sorocaba, São Paulo, Brasil. 
Perissé, around aesthetic literacy, a way to break with the crystallizations in the ways of seeing and living education; and Emmanuel Lévinas, about the responsibility to the other.

Keywords: public school; aesthetic experience; school practice.

Resumen: La escuela pública vive tiempos difíciles, en un contexto que busca descalificarla, dando preferencia a las inversiones privadas en la educación. Actualmente, es vista como inferior e incompetente ante los desafíos de la contemporaneidad. En la dimensión del concepto de ensayo de Larrosa, se busca contribuir con la temática, analizando el Proyecto Convulsivo Sinódico de la E. E. "Prof. Carlos Augusto de Camargo", de Piedade, SP, creado y desarrollado por la escuela en el período 1993-2017, a la manera de Walter Benjamin, para quien el pasado puede ser retomado y revelarse en nuevas formas en el presente, y de Roger Chartier, cómo se hace leer una realidad. La metodología utilizada es la investigación cualitativa junto a los Planes Directores y de Gestión de la escuela. Los resultados señalan caminos a ser explorados en la dimensión de Gabriel Perissé, en torno a la alfabetización estética, una forma de romper con las cristalizaciones en los modos de ver y vivir la educación; y de Emmanuel Lévinas, acerca de la responsabilidad con el otro.

Palabras clave: escuela pública; experiencia estética; práctica escolar.

\section{ESCOLA PÚBLICA: QUESTÕES CONTEMPORÂNEAS}

A escola pública (EP) convive com tempos intrincados, dentro de um contexto que visa a desqualificá-la dando preferência aos investimentos privados na educação. $O$ abandono das elites e dos setores médios passa então a fortalecer os espaços privados de ensino. Relegada aos setores populares, a escola pública "perde valor não só econômico, mas também simbólico, produzindo a desvalorização dos diplomas e da profissão docente" (KRAWCZYK, 2014, p. 16).

As instituições escolares constituem-se de resultados da confluência de fatores sociais, políticos, econômicos, culturais, e esse processo explica as características de sua configuração, "sua identidade original, os modos que se articula com a ordem social e a especificidade que sustenta sua identidade" (TIRAMONTI, 2014, p. 188). Por outro lado, Enguita (2014, p. 9) diz que há um conflito aberto e encoberto entre a sociedade e a instituição escolar. Numa alegoria, traz o encontro das águas dos Rios Negro e Solimões, que correm por quilômetros, sem se misturar.

Roger Chartier (2002, p. 22), ao se referir à representação, diz que ela pode ostentar uma realidade que não é. Para ele: “Assim deturpada, a representação transforma-se em máquina de fabrico, de respeito e de submissão, num instrumento que produz constrangimento interiorizado". A EP hoje é representada como inferior e incompetente diante dos desafios que ela não consegue vencer, em 
face da complexidade instalada em sua estrutura; eis que ela se tornou extensão dos conflitos e das desigualdades sociais.

Em 2017, o Congresso Internacional "Escola Pública: tempos difíceis, mas não impossíveis", realizado pela Faculdade de Educação da UNICAMP, tinha entre seus objetivos o de "afirmar a positividade da escola pública e construir novos caminhos para seu futuro" (COMISSÃO ORGANIZADORA, 2017). Uma iniciativa louvável, que provocou alertas sobre o contexto atual dessa instituição, tão desqualificada perante a opinião pública, sendo justamente um âmbito de formação de subjetividades, em que é possível deixar de ser o que se é, escapar de si mesmo, experimentar a igualdade de qualquer um com qualquer outro (LARROSA, 2017, p. 364).

Nora Krawczyk, organizadora do evento, ao tratar da desqualificação de demonização da EP perante a opinião pública, evidencia que a EP é um espaço estratégico de formação de valores, portanto fundamental numa sociedade democrática e independente. Em sua defesa, apresenta um brado textual: "Quando a escola pública é atacada, a juventude é atacada e a nação é atacada" (KRAWCZYK, 2018, p. 10).

Estigmatizada, a EP busca alternativas, desenvolve iniciativas, culturas intrínsecas em diferentes unidades de ensino, na expectativa de encontrar caminhos à sua sustentação e sobrevivência. Conforme Guillermina Tiramonti:

Neste contexto, os Estados e as instituições começaram a introduzir modificações no dispositivo institucional tanto para melhorar as possibilidades de retenção escolar, como para tornar a escola mais atrativa para os jovens e aproximar-se (não sem dificuldades) da cultura contemporânea. (TIRAMONTI, 2014, p. 190).

Larrosa e Kohan (2017, p. 9) dizem que: "Se alguma coisa nos anima a educar é a possibilidade de que esse ato de educação, essa experiência em gestos, nos permita liberar-nos de certas verdades, de modo a deixarmos de ser o que somos para ser outra coisa para além do que vimos sendo". A experiência é o que acontece com as pessoas e, ao acontecer, forma-as ou transforma-as, marcandoas na maneira de ser (LARROSA, 2017, p. 332).

Larrosa (2003, p. 103) traz também a inspiração para essa tessitura textual: o ensaio. Para ele, talvez estejamos vivendo bons tempos para essa forma híbrida e impura da escrita, algo que se abre ao tempo em que se caminha, ensaiando fundamentos, hipóteses, sem a pretensão de ter esgotado o tema. 
Seguindo o "caminho da exploração" proposto pelo autor (LARROSA, 2003, p. 112), este texto traz uma experiência vivida pela Escola Estadual "Prof. Carlos Augusto", na cidade de Piedade, SP, denominada de Projeto Convulsivo Sinódico, criado e desenvolvido na escola por vinte e um anos.

Trata-se de um exercício criativo, que, na esteira de buscar novas forças de agir e pensar, exercita a disposição interior para vivenciar, apreciar, avaliar e interpretar melhor o que é visto e ouvido: é a educação estética, na concepção de Gabriel Perissé, para quem a arte educa influenciando formas de sentir e pensar, por meio de artistas, condutores de extremos, a quem denomina de "educadores perturbadores" (PERISSÈ, 2009, p. 38).

O caminho proposto se nutre da discussão à maneira de: Walter Benjamin (GAGNEBIN, 1994, p. 16), para quem o passado pode ser retomado por meio de suas ruínas - eis que inacabado, pode revelar-se nas linhas do presente sob novas formas; e Roger Chartier (2002, p. 17), na dimensão da história cultural, que "tem por principal objeto identificar o modo como em diferentes lugares e momentos uma determinada realidade social é construída, pensada e dada a ler".

A concretude dos dados se dá na análise de registros existentes nos Planos Diretores e de Gestão da Escola encontrados no arquivo morto da instituição.

\section{EXPERIÊNCIA EM DIMENSÃO ESTÉTICA}

Walter Benjamin (1994, p. 226), ao trazer o quadro "Angelus Novus", de Paul Klee, representa um anjo que parece querer se afastar de algo que encara fixamente. Olhos escancarados, boca dilatada, asas abertas e rosto dirigido para o passado. Ele vê, em que se observa uma cadeia de acontecimentos, uma catástrofe única, que acumula ruínas. Gostaria de parar, acordar os mortos e juntar fragmentos, porém uma tempestade sopra do paraíso, prendendo suas asas. Progresso era o nome da tempestade.

O que se acumula nessas ruínas? O passado de muitas escolas públicas, que buscaram e buscam soluções em suas próprias tempestades? Como o Projeto Convulsivo Sinódico, criado e vivenciado pela escola "Carlos Augusto de Camargo", no período de 1993 (ano de sua criação) até os dias atuais, poderia contribuir para essa discussão?

A Escola Estadual "Prof. Carlos Augusto de Camargo" está estabelecida em área central de Piedade, SP, município de economia agrária, localizado na região 
metropolitana de Sorocaba. A escola atende hoje, em sua maior parte, alunos de áreas periféricas e em menor quantidade, alunos do centro de Piedade, nas modalidades do ensino fundamental, ensino médio (período da manhã e tarde) e educação de jovens e alunos (EJA) (período noturno). A comunidade atendida não se diferencia muito daquela descrita no Plano Diretor de 1995, formada de "filhos de proletários e da pequena burguesia urbana, já os alunos do Inciso III 2 o grau, do período noturno, numerosos deles maiores de 21 anos, surgem do exército industrial de reserva, parcialmente absorvido pelo capital urbano rural" (EEPSG "PROF. CARLOS AUGUSTO DE CAMARGO", 1995, p. 6).

De nome bizarro, o Projeto Convulsivo Sinódico (PCS), criado em conjunto com os professores que lá estavam, sob a coordenação pedagógica da Profa. Dra. Maria Lúcia de Amorim Soares, à maneira de Dadá, por meio de palavras extraídas aleatoriamente de um dicionário que melhor expressassem o movimento, necessita da inferência da própria autora:

[...] Projeto Convulsivo Sinódico. Convulsivo porque a trama das relações e interações sociais que antecedem o momento sinódico, momento do equilíbrio, foram realizadas num campo de forças minado por concepções de formação, representações, sentidos e significados sobre o papel da escola e de seus atores na sociedade. (SOARES, 2006, p. 65).

Nesse "campo de forças minado", deve-se considerar a mudança anual do quadro de professores e alunos, permitindo novas formas de pensar e de agir. Assim, o PCS se modifica constantemente. Numa metáfora visual - areia que penetra nas pedras. Pedras sedimentadas pelos sistemas de educação, legislações e normas a serem cumpridas, que tornam a escola, conforme informam Soares e Nogueira (2012, p. 139), um "espaço de mesmice, repetição do senso comum", situação em que "o habitual é o mais difícil de ver com olhar de estranhamento, que permite romper com as cristalizações nos modos de ver, através do acesso a vivências estéticas e seus significados". Areia que penetra entre pedras, exercitando, na dimensão de Munhoz e Zanela (apud SOARES; NOGUEIRA, 2012, p. 126), a relação estética de "uma das formas mais antigas da relação do homem com o mundo, antecedendo o direito, a política, a filosofia e a ciência".

Na prática, o projeto se inicia com a busca de um tema gerador. As ideias se originam do próprio movimento de professores e alunos, de suas ansiedades e acontecimentos. Aos poucos, vão nascendo em conversas informais, nas brechas 
do tempo/espaço e determinações pedagógico-administrativas. Essas ideias vão sendo tecidas e absorvidas, até eclodirem na reunião de planejamento, que ocorre no início do ano, momento em que se estabelece um consenso sobre a temática do projeto, que perpassa o conteúdo das disciplinas da grade curricular, como um tema transversal (Projeto Convulsivo), até finalizar em materializações artísticas do processo (Projeto Sinódico).

O PCS foi implementado na época em que a escola havia se transformado em Escola Padrão, pelo Decreto 34.035, de 22/10/1991, com a finalidade de recuperar a qualidade, modernizar a escola pública, preparar o aluno para o acesso aos níveis elevados de compreensão e intervenção na realidade e utilizar novas tecnologias educacionais. O mesmo decreto oferecia autonomia pedagógica, administrativa e liberdade de propor projetos especiais relacionados ao ensino-aprendizagem, capacitação e relações com a comunidade.

As autonomias aliadas às ações previstas como enriquecimento curricular, que permitiram dar corpo ao PCS - entre elas: realização de palestras, debates sobre temas atuais de interesse e/ou conveniência da comunidade escolar, projeto de filmes que levassem à discussão/reflexão dos alunos; realização de peças ou apresentações, shows, festivais, concurso de música, dança, poesia; realização de visitas e excursões; organização de oficinas de criatividades (SARMENTO; ARRUDA, 2011, p. 6) -, são ações que estimulavam e davam possibilidades ao exercício criativo em dimensão estética, realizado pelos atores da escola.

A proposta da implantação da Escola Padrão, alicerçada à vontade de um grupo de professores conscientes e determinados, que faziam parte da instituição, constituiu-se em terreno fértil para uma "revolução invisível", que buscava o encontro de identidades:

A construção de uma Escola Padrão é lenta e celular. Para se fazer a construção visível, há necessidade de existir a revolução invisível. É esta que se pretende, em primeiro plano com o resgate da identidade profissional, identidade do educando, identidade da EEPSG. "Prof. Carlos Augusto de Camargo". (EEPSG PROF. CARLOS AUGUSTO DE CAMARGO, 1995, p. 61).

O PCS foi então se integrando à dinâmica da Escola, desde 1993, e se tornou mais concreto na Proposta Educacional/1995. Nas palavras da Profa. Maria Lúcia: "Compareço com a Proposta Educacional 1995, porque concebida com magnitude, trama que se monta a partir de fevereiro de 1993, átimo da 'transformação' da 
escola em Escola Padrão" (SOARES, 2001, p. 27). Incorporada ao Plano Escolar da EEPSG "Prof. Carlos Augusto de Camargo", de 1995, a proposta imprime colocações que se fazem atuais:

Uma proposta educacional exige valores fundamentais a serem trabalhados pela escola. Na EEPSG. "Prof. Carlos Augusto de Camargo" permeia a consciência de que existe uma transformação cultural emergente na sociedade. A natureza e a profundidade dessa transformação são discutíveis, mas transformação ela é. A mutação na sensibilidade, nas práticas e nos discursos da aceitação do efêmero, do fragmentário, do descontínuo e do caótico. A imagem, a aparência, o espetáculo são experimentados com intensidade pelos jovens. O caráter imediato dos eventos forja uma consciência relacionada só ao presente, desprezando o tempo histórico.

Televisão e vídeo subjugam o homem. Bancos eletrônicos, cartões de plástico, alimentos e refeições instantâneas, a descartabilidade das xícaras, dos pratos, das roupas, a volatilidade dos signos e imagens, a queda das barreiras espaciais... forjam um mundo novo. Coletivamente, encontram-se o corpo administrativo e docente diante da pergunta crucial: o que fazer? (SOARES, 2001, p. 27-8).

A pesquisa junto aos Planos Diretores/Gestão da Escola evidenciou a força da gênese do projeto, em especial a dos primeiros realizados, que, aliada ao momento em que a estrutura institucional da unidade escolar permitiu maior autonomia pedagógica, em função do Projeto da Escola Padrão, pôde oportunizar o exercício de processos criadores, capazes de provocar movimentos desestabilizadores do cotidiano escolar. Processos criadores que, na concepção de Maherie, Zanella e Das Ros (2007 apud SOARES; NOGUEIRA, 2012, p. 129), "se distanciam dos processos tradicionais de ensino, carregados de relações verticalizadas, para chegar a saberes que envolvem a constituição do sujeito como um todo, do aluno como também do professor, que se protagonizam ao criarem novas pedagogias, recriando-se".

Em 1995, a proposta educacional do "Carlos Augusto" (SOARES, 2001 p. 28) apresentava síntese de diretrizes e metas, observando a "transformação cultural existente na sociedade". Alertava para uma "mutação na sensibilidade" nas "práticas e nos discursos", que exigiam uma nova forma de pensar. 
Quadro 1 - Proposta Educacional do "Carlos Augusto"

\begin{tabular}{|l|l|}
\hline \hline Diretrizes & Metas \\
\hline $\begin{array}{l}\text { 1. Praticar a comunidade escolar para } \\
\text { ser feliz. }\end{array}$ & 1. Dar forma corpórea à busca da felicidade. \\
\hline $\begin{array}{l}\text { 2. Refinar a qualidade educacional, } \\
\text { extirpando a ganga impura. }\end{array}$ & $\begin{array}{l}\text { 2. Inculcar a produtividade qualitativa do } \\
\text { corpo docente, discente e administrativo. }\end{array}$ \\
\hline $\begin{array}{l}\text { 3. Impulsar a leitura do mundo no } \\
\text { instante "pós-moderno". }\end{array}$ & $\begin{array}{l}\text { 3. Embriagar-se na paixão de conhecer e } \\
\text { viver o mundo contemporâneo. }\end{array}$ \\
\hline $\begin{array}{l}\text { 4. Pelear pela cidadania e democracia } \\
\text { competentes. }\end{array}$ & $\begin{array}{l}\text { 4. Peludear pelos direitos e frondejar de- } \\
\text { veres. }\end{array}$ \\
\hline \hline
\end{tabular}

Fonte: Soares (2001, p. 28).

As diretrizes apresentadas, que orientam o PCS, ainda hoje causam estranhamento junto à Diretoria de Ensino, na qual a instituição escolar está atrelada. Todavia essas diretrizes estão integradas ao atual Plano de Gestão da Escola (quatrienal, 2014 a 2017) e, portanto, ao seu Projeto Político-Pedagógico, materializando uma cultura escolar que se formou dentro da instituição, cujo conceito pode ser extraído de Viñao Frago (2002, p. 59):

La cultura escolar, así entendida, estaría constituida por un conjunto de teorías, ideas, principios, normas, pautas, rituales, inercias, hábitos y prácticas (formas de hacer y pensar, mentalidades y comportamientos) sedimentadas a lo largo del tiempo en forma de tradiciones, regularidades y reglas de juego no puestas en entredicho y compartidas por sus actores, en el seno de las instituciones educativas.

\section{RELAÇÕES DE IDENTIDADE}

Sarmento e Arruda (2011, p. 3), numa alusão ao Projeto da Escola Padrão, que foi se esvaziando gradativamente a partir de 2005, sendo totalmente revogado pela Resolução SE 63, de 20/08/2008, dizem que o processo educativo brasileiro é "um constante recomeçar, sem continuidade". A inferência das autoras permite trazer Roger Chartier (2002, p. 25), o qual defende a relação das "modalidades do agir e do pensar", que "devem ser sempre remetidas para os laços de interdependência que regulam as relações entre os indivíduos e que são moldados de diferentes maneiras em diferentes situações, pelas estruturas do poder". 
Muito mais do que um laboratório de ideias e projetos externos da "estrutura do poder", a instituição escolar é um espaço vivo de metamorfoses, com características e culturas próprias, em que o assentamento de inserções externas se dá de formas e maneiras diferenciadas, através de conexões/alterações por meio de diferentes atores e experiências.

A pesquisa demonstrou conexões entre o PCS e a instituição escolar ao longo dos anos, mas também alterações. Ao analisar o Plano Diretor da escola de 2005, não se observa qualquer menção ao projeto, embora, na prática, ele acontecesse de forma diferenciada dos primeiros realizados.

Ao longo dos anos, algumas lacunas foram produzidas pela não aceitação do PCS em função da complexidade das questões teóricas nele envolvidas, apesar da importância da discussão de sua gênese para o enfrentamento de questões contemporâneas. Observa-se que no ano de 2017 o projeto deveria contemplar sua 25a edição, mas contemplou a 21a. Traz-se aqui a concepção de cultura escolar de Dominique Julia, para quem a cultura escolar deve ser entendida dentro das relações conflituosas ou pacíficas que ela mantém, em cada período da história com a contemporaneidade. Para ele, "Mais que nos tempos de calmaria, é nos tempos de crise e de conflitos que podemos captar melhor o funcionamento real das finalidades atribuídas à escola" (JULIA, 2001, p. 19).

Se, por um lado, alguns planos diretores e de gestão encontrados na escola apresentaram rupturas na continuidade do projeto, a pesquisa evidenciou sua retomada em outros, inclusive no de 2014, que compreende o quadriênio 2014/2017, homologado pela Diretoria de Ensino, à qual a escola está atrelada. Todavia a vivência do projeto mostrou uma continuidade diferente quanto à magnitude dos primeiros realizados - evidência manifestada no próprio tempo de duração do Projeto Sinódico, momento da materialização da efervescência de estudos, pesquisas e criações. Se, nos primeiros projetos, seu desenvolvimento preenchia o espaço temporal de uma semana, atualmente, é de apenas um dia.

Há de se observar as dificuldades de sobrevivência de projetos criados na e pela própria instituição escolar. Para Julia (2001, p. 12), existe uma utopia contemporânea de visão idílica da "potência absoluta dos projetos pedagógicos". Essa potência tem: "pouco a ver com a história sociocultural da escola e despreza as resistências, as tensões e os apoios que os projetos têm encontrado em sua 
execução". Tensões resultantes do "campo de forças minado" (SOARES, 2006, p. 1) instalado e da organização espaço/temporal, dentro e fora da Escola, pela sua própria dinâmica e pelos sistemas de educação estadual/nacional.

Todavia a repetição do projeto durante vinte e um anos, no período 1993/2017, demonstrou relativa autonomia, continuidade e persistência no tempo, fatores que permitem dizer que houve uma relação de identidade entre o "Carlos Augusto" e o PCS, na qual se forjou uma cultura escolar. Como bem observa Viñao Frago: "La cultura escolar sería, en síntesis, algo que permanece y que dura; algo que las sucesivas reformas no logran más que arañar superficialmente, que sobrevive a ellas, y que constituye un sedimento formado a lo largo del tempo" (VIÑAO FRAGO, 2002, p. 59).

\section{PROJETO CONVULSIVO SINÓDICO: GÊNESE E ATUALIDADE}

Na cerimônia de abertura do XIII Congreso Iberoamericano de Historia de la Educación en América Latina, realizado no início de 2018, em Montevideo, Uruguai, o Prof. Jorge Bralich finalizou seu discurso dizendo da importância de buscar novas respostas e interpretações para a realidade e que é preciso intercambiar experiências como educadores. Ao compreender a história da educação como a continuidade do conhecimento, enquanto um processo acumulativo, disse que cada um, ao desenrolar sua história própria, apresentaria aportes importantes para entender a relação educação e sociedade.

O pronunciamento do educador encoraja a compartilhar uma experiência, cuja gênese poderia ter se silenciado no passado. Walter Benjamin mostra a importância de salvar o passado no presente, "graças à percepção de uma semelhança que os transforma os dois:

[...] transforma o passado porque este assume uma forma nova, que poderia ter desaparecido no esquecimento; transforma o presente porque este se revela como sendo a realização possível dessa promessa anterior, que poderia ter-se perdido para sempre, que ainda pode se perder se não a descobrirmos, inscrita nas linhas do atual. (GAGNEBIN, 1994, p. 16).

Nessa dimensão, são apresentados fragmentos do PCS, em dois momentos de sua história: o de sua gênese (1993 e 1994) e outro recente, desenvolvido em 2017; espaços temporais do projeto vividos por seus atores - corpo discente, docente, coordenação pedagógica e direção do "Carlos Augusto", em Piedade. 
Em 1993, o "Carlos Augusto" realizou o 1ㅇ PCS, com o tema "Memórias da Escola", em que o arquivo morto foi revisitado e dele foram retirados "fantasmas" da escola constituídos por objetos de sua história escondidos e esquecidos. Bandeiras, flâmulas, mimeógrafos, instrumentos musicais e máquinas de escrever em desuso foram espalhados pelos corredores como instalações artísticas, a maneira do conceito de ready-made de Duchamp (LIMA 2017), em que elementos da vida cotidiana, sem atributos artísticos, transformam-se em obras de arte. No teto da entrada da sala dos professores, um fragmento da proposta educacional que nascia: "Romper pelo estranhamento o arquivo morto, que é a instituição escolar, que se pretende umbigo do mundo" (EEPSG. "PROF. CARLOS AUGUSTO DE CAMARGO", 1995, p. 110).

Os "fantasmas" levavam a comunidade escolar a pensar e narrar histórias sobre a instituição enquanto espaço vivo da história da educação do município e da sua própria, na perspectiva de Walter Benjamin (1987, p. 201): “O narrador retira da experiência o que ele conta: sua própria experiência ou relatada pelos outros. E incorpora as coisas narradas à experiência de seus ouvintes". O projeto "Memórias da Escola" foi compartilhado com toda a comunidade escolar.

Essa mesma temática foi revisitada em 2013, com o 13으 PCS, denominada de "Caça aos tesouros - redescobertas", projeto no qual foram reencontrados instrumentos da antiga fanfarra empoeirados num dos arquivos/depósito da escola, e, através de parcerias realizadas junto do MEC/Projeto Mais Educação e da Prefeitura de Piedade, a fanfarra, tão premiada no passado, pôde ser reconstituída e transformada numa Banda Marcial - banda que também foi premiada em dois concursos de âmbito estadual, em 2015 e 2016, que trouxe orgulho e exercício de pertencimento à comunidade escolar.

O segundo PCS ocorreu em 1994 e denominou-se de "Fractais", tema gerador extraído de teorias que fundamentavam a proposta educacional:

Teoria do Caos e Teoria das Catástrofes. Explicitando: as fractais de Mandelbrot, formas irregulares, mas que expressam racionalidade e beleza. A Teoria do Caos porque informa que "dentro da desordem existe ordem". A Teoria das Catástrofes porque tem como objetivo explicar e predizer os fenômenos descontínuos. (EEPSG "PROF. CARLOS AUGUSTO DE CAMARGO", 1995, p. 4).

"Fractais" propunha, no primeiro bimestre de 1994, pesquisas, entrevistas com intelectuais, artistas plásticos, músicos, como registra o Plano Diretor de 1995: 
[...] foi criado o Projeto Convulsivo Sinódico, com desenvolvimento no primeiro semestre (pesquisas, entrevistas com intelectuais, artistas plásticos, músicos, definição de áreas e temas), com efetivação dos trabalhos na Semana Convulsiva Sinódica (4ạ semana de agosto) e apresentação pública na Semana Sinódica (1a semana de setembro), no Clube Literário e Recreativo de Piedade" (EEPSG “PROF. CARLOS AUGUSTO DE CAMARGO”, 1995, p. 107).

Entre os entrevistados, estava o artista Eduardo Iglesias, que na época contava com uma exposição denominada "Wagneriana", constituída por telas inspiradas nas óperas de Richard Wagner. A entrevistadora, coordenadora do ensino médio, inteirada da proposta de Iglesias, realizou um intercâmbio de experiências entre a concepção do artista e exercício dos alunos ao pintarem lenços de seda, os quais foram expostos na materialização do Projeto Sinódico.

Também foi entrevistada a designer brasileira de bijuterias e acessórios Rose Benedetti, para quem foram apresentadas algumas peças elaboradas pelos alunos trabalhadores do período noturno da escola. As peças foram inspiradas em pinturas de paredes e desenhos na areia, à maneira do povo quioco, residente no leste de Angola, na África. Os alunos transpuseram para o material utilizado em suas profissões a linguagem dos quiocos. As bijuterias foram confeccionadas em material reciclado de oficinas de automóveis e produtos da terra, como a casca da cebola e da cenoura. O trabalho causou estranhamento à artista, pela criatividade e pelo desempenho da escola pública, num pequeno município de economia agrícola do interior do estado de São Paulo.

A finalização de "Fractais" ocorreu com uma apresentação pública no Clube Literário e Recreativo, denominada de "A Grande Tela", no centro da cidade - e lá permaneceu por uma semana, com espetáculos de dança, performances, desfiles de moda, mostras de roupas, lenços e bijuterias criados pelos alunos e artesanatos confeccionados pelas famílias. O movimento foi tão intenso, que chegou a ser considerado, pelos mais integrados ao projeto, como a "Semana de Arte Moderna de Piedade".

A 21a edição do PCS, em 2017, teve como tema: "Piedade: nossos caminhos, nossa terra e nossa gente". A temática rendeu a publicação de onze textos de alunos, com fotos e informações sobre seus autores, no Jornal Folha de Piedade, ocupando oito páginas da 565a edição desse jornal semanal, que circula em todo o município. O editorial teve o título "Jovens ensinam governantes: aprendam a ouvir" e abordou a importância do diálogo com todos os segmentos da sociedade, 
entendendo as sugestões contidas nos textos dos alunos como forma de debater as carências coletivas da população piedadense (FOLHA DE PIEDADE, 2017, p. 2). A publicação, que tinha como título "A Piedade que eles querem", fez referência à tradição do projeto no município:

Na semana em que se comemora 177 anos do município, a Folha de Piedade ouviu aqueles que constroem o futuro da cidade. Onze estudantes da escola "Carlos Augusto de Camargo" expuseram sua visão, o que pensam de Piedade. A iniciativa consistiu em parceria entre a instituição de ensino e o jornal e foi parte integrante do tradicional projeto Convulsivo Sinódico. (FOLHA DE PIEDADE, 2017, p. 13).

Diferentemente da gênese do projeto (1993, 1994), o PCS sobreviveu em outros formatos. Em geral, partindo de clássicos literários, com temas a eles relacionados e que perpassam o conteúdo das disciplinas contidas na grade curricular durante o ano. Em sua finalização, ou Projeto Sinódico, momento de equilíbrio do "campo de forças", há uma exposição aberta à comunidade, com mostras de instalações, teatros, danças e outras manifestações artísticas. Em 2017, os professores, na reunião de planejamento, optaram por estudar a história de Piedade, por meio de livros escritos por seus historiadores.

O projeto materializado na temática proposta apresentou história e costumes de Piedade em diferentes representações artísticas. Uma delas foi a instalação "Cidade de Papel", criada e elaborada pelos alunos, sob a orientação dos professores de matemática, que utilizaram conceitos extraídos da geometria. A instalação foi transplantada para a Casa da Cultura de Piedade, a convite de autoridades ligadas à Cultura e ao Turismo do município, lá permanecendo por um mês para visita de toda a população.

\section{CONSIDERAÇÕES}

As "tempestades" que povoam a EP estão instaladas em sua própria crise, rebento da sociedade e de sua cultura. Soares (2001, p. 27-8), ao tratar da proposta educacional da escola "Carlos Augusto", disse que há um mundo novo que vem sendo forjado, fruto de uma transformação cultural emergente na sociedade, que envolve a mutação da sensibilidade, práticas, discursos, numa consciência relacionada só ao presente, desprezando o tempo histórico. Por isso, questiona: "O que fazer?". 
Edward Thompson (2002, p. 13) escreveu que a experiência "modifica, às vezes de maneira sutil e às vezes radicalmente, todo o processo educacional, influencia os métodos de ensino, a seleção e o aperfeiçoamento dos mestres e os currículos". Exercitando respostas, a escola "Carlos Augusto", em Piedade, realizou e continua realizando experiências em torno do PCS, que rompe com o emparedamento curricular, tornando-o flexível, realiza rupturas e desperta a consciência dos alunos com os limites da própria escola.

O projeto sobrevive, apesar das modificações ocorridas em seus vinte e um anos de existência, suspende o cotidiano e deixa sequelas que permitem impulsionar novas temáticas, aliadas aos temas e às leituras literárias nascidas das ansiedades da própria escola, em dimensão artística.

Seu exercício anual inquieta, provoca viagens metamorfoseadas em salas de aula. Paredes-cenários, alunos autores, atores, estilistas, sonoplastas, fotógrafos, conduzidos pelos temas estudados, com espaços materializados a partir da imaginação. Criação e fruição. Cenários propícios aos encontros abertos com o outro.

São entrelaçamentos e construções de subjetividades em que se permite trazer Lévinas (1982, p. 88), num movimento de gangorra que balança o olhar face a face e traz responsabilidade com o outro. Movimento diverso da impessoalidade que tantas vezes reina no cotidiano escolar, em contextos, aprendizagens e relações humanas fragmentadas, com olhares distantes que não se voltam para os rostos.

Gabriel Perissé (2009, p. 8), ao tratar de estética e educação, pontua que ela pode contribuir para a vida intelectual e profissional do professor. Propõe uma "alfabetização estética" para que não se corra o risco de praticar uma educação limitada e limitadora e identifica um quadro de "miséria espiritual" embutido no desprestígio social da função docente, em que a educação é transformada em mercadoria.

Essa alfabetização permite trazer Soares (2001, p. 17) e o tensionamento do fazer da vida na busca de "um passado que não cessa de passar e de um futuro que não se encontra sem construção", na voz do poeta argentino Oliverio Girondo:

[...] a vida é um longo embrutecimento. O costume nos tece, diariamente, uma teia de aranha nas pupilas; pouco a pouco, aprisionam-nos a sintaxe, o dicionário; os mosquitos podem voar tocando corneta, carecemos de chamá-los arcanjos e quando desejamos viajar nos dirigimos a uma agência de vapores em vez de metamorfosear uma cadeira em transatlântico. (SOARES, 2001, p. 17). 
Sem respostas imediatas para a crise da escola pública, é possível "ensaiar" propostas na dimensão de Lévinas, presentes na responsabilidade com o outro, e de Perissé (2009, p. 12), para quem "A realidade artística necessita ser experimentada pessoalmente a fim de que se joguem luzes sobre as definições que buscamos com a razão... e o coração".

\section{REFERÊNCIAS}

BENJAMIN, Walter. Magia e técnica, arte e política: ensaios sobre literatura e história da cultura. Tradução de Sergio Paulo Rouanet. 7. ed. São Paulo: Brasiliense, 1994. 253p.

BRALICH, Jorge. Diálogo de abertura: las condiciones de posibilidad de la Reforma de 1918. In: CONGRESO IBEROAMERICANO DE HISTORIA DE LA EDUCACIÓN LATINOAMERICANA: A 100 AÑOS DE LA REFORMA DE CÓRDOBA, 13., 2018, Montevideo, Uruguay. Caderno de resumos [...]. Montevideo, Uruguay: Sociedad Uruguaya de Historia de la Educación, 2018. p. 13.

CHARTIER, Roger. A história cultural entre práticas e representações. Tradução de Maria Manuela Galhardo.2. ed. Lisboa: Difusão Editorial, 2002. 244 p.

COMISSÃO ORGANIZADORA [do] Congresso Internacional "Escola Pública: tempos difíceis, mas não impossíveis". Campinas, SP, Faculdade de Educação da UNICAMP, 2017. Disponível em: https://www.fe.unicamp.br/agenda-de-eventos/2767. Acesso em: 26 mar. 2018.

E. E. "PROF. CARLOS AUGUSTO DE CAMARGO”. Plano de Gestão da Escola. Piedade, SP, 2014.

E. E. "PROF. CARlos AuguSto de CAMARGO". Plano Diretor da Escola. Piedade, SP, 2005.

EEPSG. “PROF. CARLOS AUGUSTO DE CAMARGO”. Plano Diretor da Escola. Piedade, SP, 1995.

EEPSG. "PROF. CARLOS AUGUSTO DE CAMARGO”. Plano Diretor da Escola Padrão. Piedade, SP, 1993.

ENGUITA, Mariano Fernández. A encruzilhada da instituição escolar. In: KRAWCZYK, Nora (Org.). Sociologia do Ensino Médio: crítica ao economicismo na política educacional. São Paulo: Cortez, 2014. p. 7-11.

FOLHA DE PIEDADE. Piedade, SP, ano 10, n. 565, 19 maio 2017.

GAGNEBIN, Jeanne Marie. Walter Benjamin ou a história aberta. In: BENJAMIN, Walter. Magia e técnica, arte e política: ensaios sobre literatura e história da cultura. Tradução de Sergio Paulo Rouanet. 7. ed. São Paulo: Brasiliense, 1994. 
JULIA, Dominique. A cultura escolar como objeto histórico. Revista Brasileira de História da Educação, Campinas, SP, n. 1, p. 9-43, jan./jun. 2001. Disponível em: http://periodicos. uem.br/ojs/index.php/rbhe/article/view/38749. Acesso em: 9 nov. 2017.

LARROSA, Jorge; KOHAN, Walter (Coord.). Apresentação da coleção. In: LARROSA, Jorge. Pedagogia profana: danças, piruetas e mascaradas. 6. ed. rev. amp. Belo Horizonte: Autêntica. 2017. p. 9-10. (Coleção: Educação, experiência e sentido).

KRAWCZYK, Nora. Introdução. In: KRAWCZYK, Nora. Escola pública: tempos difíceis, mas não impossíveis. Campinas, SP: FE/UNICAMP; Uberlândia, MG: Navegando, 2018. p. 10-2.

KRAWCZYK, Nora. Conhecimento crítico e política educacional: um diálogo difícil, mas necessário. In: KRAWCZYK, Nora (Org.). Sociologia do Ensino Médio: crítica ao economicismo na política educacional. São Paulo: Cortez, 2014. p. 13-32.

LARROSA, Jorge. O ensaio e a escrita acadêmica. Revista Educação e Realidade, Porto Alegre, v. 28, n. 2, p. 101-15, jul./dez. 2003. Disponível em http://seer.ufrgs.br/ educacaoerealidade/article/view/25643/14981. Acesso em: 25 set. 2018.

LÉVINAS, Emmanuel. Ética e infinito. Diálogos com Philippe Nemo. Lisboa, Portugal: Edições 70, 1982. 105 p.

LIMA, Juliana Domingos. A 'Fonte' de Duchamp faz cem anos. Qual foi o impacto (e o legado) do mictório como obra de arte. 2017. Disponível em https://www.nexojornal.com.br/ expresso/2017/03/05/A-\%E2\%80\%98Fonte\%E2\%80\%99-de-Duchamp-faz-cem-anos.-Qualfoi-o-impacto-e-o-legado-do-mict\%C3\%B3rio-como-obra-de-arte. Acesso em: 3 abr. 2018.

PERISSÉ, Gabriel. Estética e educação. Belo Horizonte: Autêntica, 2009. 100 p.

PUC-RIO. Emmanuel Lévinas, o outro e a alteridade. Rio de Janeiro. Disponível em: https:// www.maxwell.vrac.puc-rio.br/13482/13482_4.PDF. Acesso em: 20 jan. 2019.

SÃO PAULO (Estado). Decreto n. 34.035, de 22 de outubro de 1991. Disponível em: https:// governo-sp.jusbrasil.com.br/legislacao/181563/decreto-34035-91. Acesso em: 5 jul. 2017.

SARMENTO, Albertina Paes; ARRUDA, Aparecida Luvisotto M. Martins. Escola Padrão, curta-vida, longa saudade. Revista Eletrônica Saberes da Educação, São Roque, SP, v. 2, n. 1, p. 1-22, 2011. Disponível em: http://docs.uninove.br/arte/fac/publicacoes/pdf/v2n1-2011/Albertina.pdf. Acesso em: 25 mar. 2018.

SOARES, Maria Lúcia de Amorim. De história e práticas: o Projeto Convulsivo - Sinódico do "Carlos Augusto" de Piedade/SP. Revista HISTEDBR On-line, Campinas, SP, n. 21, p. 65-73, 
mar. 2006. Disponível em: https://periodicos.uff.br/revistaleph/article/view/39009. Acesso em: 20 jan. 2019.

SOARES, Maria Lúcia de Amorim. Girassóis ou heliantos: maneiras criadoras para o conhecer geográfico. Sorocaba, SP: Prefeitura Municipal, Prêmio Linc, 2001. 182 p.

SOARES, Maria Lúcia de Amorim; NOGUEIRA. Eliete Jussara. Educação estética: alguns princípios orientadores para práticas pedagógicas emancipatórias no cotidiano escolar. RevistAleph. UFF, Rio de Janeiro, ano VI, n. 18, p. 126-41, dez. 2012. Disponível em: http:// revistaleph.uff.br/index.php/REVISTALEPH/article/viewFile/39/34. Acesso em: 23 jul. 2017.

THOMPSON, Edward Palmer. Educação e experiência. In: THOMPSON, Edward Palmer. Os românticos: a Inglaterra e a era revolucionária. Rio de Janeiro: Civilização Brasileira, 2002. p. 11-47.

TIRAMONTI. Guilhermina. A escola moderna. Restrições e potencialidade frente às exigências da contemporaneidade. In: KRAWCZKY, Nora. (Org.). Sociologia do Ensino Médio: crítica ao economicismo na política educacional. São Paulo: Cortez, 2014. p. 185-206.

VIÑAO FRAGO, Antonio. Sistemas educativos, culturas escolares y reformas: continuidades y câmbios. 2002. 106 p. Disponível em: http://www.oei.org.ar/edumedia/pdfs/T05_ Docu3_Sistemaseducativosculturasescolares_Vinao.pdf. Acesso em: 4 dez. 2017.

\section{Sobre as autoras:}

Sônia Aparecida Ijano Batista: Doutoranda na Universidade de Sorocaba (UNISO), no Programa de Pós-Graduação em Educação (PPGE), na linha de História e Historiografia: Políticas e Práticas Escolares. Participa do Grupo de Pesquisas em História da Educação. E-mail: soniaibtt@gmail.com, Orcid: http://orcid.org/0000-0003-2537-3930

Vânia Regina Boschetti: Doutora em Ciências pela Universidade de São Paulo (USP). Docente do Programa de Pós-Graduação em Educação da Universidade de Sorocaba (UNISO).E-mail: vania.boschetti@prof.uniso.br, Orcid: http://orcid.org/0000-0001-5119-2987

\section{Recebido em 28 de março de 2019.}

Aprovado em 18 de dezembro de 2019. 
